\title{
Consumo e Desempenho de Novilhas em Pastagem Recebendo Suplementos com Diferentes Níveis de Proteína Não-Degradável no Rúmen
}

\author{
Marinaldo Divino Ribeiro ${ }^{1}$, José Carlos Pereira², Ricardo Augusto Mendonça Vieira ${ }^{3}$, Bevaldo \\ Martins Pacheco ${ }^{4}$, Fernando de Paula Leonel ${ }^{5}$
}

\begin{abstract}
RESUMO - O consumo e o desempenho de 15 novilhas Gir-Holandesas (cinco por tratamento) com 16,5 \pm 4,2 meses e 211,97 \pm 34,28 kg de peso vivo (PV), em pastagem, recebendo suplementos com 40 ou 60\% de proteína não-degradável no rúmen (PNDR), foram avaliados. A disponibilidade de forragem foi monitorada para manter oferta de 6\% PV. Para determinar o consumo empregouse o óxido crômico (10 g/dia/novilha) como indicador externo e fibra em detergente neutro indigerível (FDNI), como indicador interno. Após estimativa do consumo de matéria seca (MS), proteína bruta (PB), fibra e FDNI, os valores foram ajustados à covariável massa média corporal das novilhas, aplicando-se a relação alométrica, e expressos em função da unidade de tamanho metabólico. As novilhas foram pesadas em jejum no início e final do período experimental, com vistas a avaliar o ganho de peso. As novilhas lotadas no tratamento constituído de pastagem + suplemento consumiram em torno de 1,8 kg/MS/dia de concentrado, oferecido em duas porções diárias (8 e 16 h). Foram encontrados efeitos significativos de tratamento, período e interação para todas as variáveis de consumo de forragem e da ração total, não havendo efeito de tratamento apenas para consumo de MS e PB da ração total. Observou-se, portanto, que o consumo foi influenciado pela qualidade da pastagem e pela oferta de nutrientes extras contidos nos suplementos com níveis crescentes de PNDR e, no caso específico de FDNI, acrescenta-se a influência da covariável. O fornecimento de suplementos com níveis crescentes de PNDR (40 ou 60\%), quando comparados entre si ou com o ganho obtido em pastagem, não proporcionou ganhos diferenciados no período de transição águas-seca, sendo a média igual a 509 g/animal/dia.
\end{abstract}

Palavras-chave: fibra indigerível, ganho de peso, recria de novilhas

\section{Intake and Production of Heifers at Pasture Supplemented with Different Levels of Rumen Undegradable Protein}

ABSTRACT - The objective of this trial was to study the intake and production at pasture of 15 Holstein-Gyr heifers (5 per treatment) averaging $16.5 \pm 4.2$ months of age and $211.97 \pm 34.28 \mathrm{~kg}$ of body weight (BW) and fed supplements containing either $40 \%$ or $60 \%$ of rumen-undegradable protein (RUP). Forage availability was monitored to maintain a supply of $6 \%$ of BW. Both chromic oxide (10 g/day/heifer) and indigestible neutral detergent fiber (INDF) were used as external and internal markers, respectively. Intakes of dry matter (DM), crude protein (CP), fiber, and INDF were estimated and adjusted to the average body mass of the heifers as the covariable applying an allometric relationship and were then expressed in metabolic size unit. Weight gain was measured at the beginning and end of the experimental period in fasted heifers. Heifers at the pasture + supplement treatment consumed approximately $1.8 \mathrm{~kg}$ of concentrate DM per day that was offered at 8 a.m. and 4 p.m. Except for intakes of DM and CP of the total diet (pasture + supplement), significant treatment, period, and interaction effects were found for all remaining intake variables of forage and total diet. Therefore, intake was affected by pasture quality and supply of extra nutrients from the supplements with increasing RUP levels and for intake of INDF the use of the covariable was worthwhile. No significant changes on weight gain of heifers were observed within the different levels of RUP (40 vs. 60\%) as well as comparing supplementation versus pasture alone and averaged 509 g/animal/day during the water-dry transition period.

Key Words: heifer reraising, indigestible fiber, weight gain

\section{Introdução}

A centralização de esforços em um único segmento da cadeia produtiva leiteira, animais em produção, gera desequilíbrios que expõem o grau de ineficiência da atividade. Um dos principais componentes do sistema que agrega ineficiência de grau variado à atividade é a produção de novilhas para reposição das matrizes de descarte (Hoffman \& Funk, 1992). A fase de recria, da desmama até a gestação/parto, é quase sempre negligenciada pelos produtores, que, submetendo as novilhas à pastagem marginal de menor

\footnotetext{
${ }^{1}$ Mestre em Zootecnia. Departamento de Zootecnia da UFV. CEP: 36570-000. E.mail: malldorr@yahoo.com.br

2 Professor Titular do Departamento de Zootecnia da UFV. Pesquisador do CNPq.

3 Professor Associado do Laboratório de Zootecnia e Nutrição Animal da UENF. Pesquisador do CNPq.

${ }^{4}$ Pesquisador da Empresa Capixaba de Pesquisa Agropecuária.

${ }^{5}$ Estudante de Doutorado em Zootecnia da UFV.
} 
qualidade, incompatível às exigências de crescimento e desenvolvimento das novilhas, proporcionam perda do capital investido no aleitamento, além de comprometerem a vida produtiva da futura matriz. Desse modo, a produção de novilhas de reposição, cria e recria, deve ser precedida pelo estabelecimento de criterioso planejamento, com metas e objetivos definidos, visto que a evolução genética do rebanho, a redução da idade ao primeiro parto, o aumento da vida útil produtiva e a manutenção de uma produção mais uniforme dependem da substituição anual de vacas com problemas de qualquer natureza por animais jovens, saudáveis e de potencial mais elevado (Hoffman \& Funk, 1992).

Explorar ao máximo possível os fatores primários de produção, terra e clima, compatíveis à produção de forragem consiste em uma alternativa capital na viabilização da gestão da atividade. As gramíneas forrageiras tropicais são altamente eficientes na utilização do nitrogênio e no acúmulo de biomassa vegetal e igualmente eficazes na deposição de material estrutural lignificado em nível de parede celular à medida que crescem (Paciullo, 2002), o que reduz seu potencial de uso. Sob essas condições, o consumo animal pode ser limitado pelo rápido enchimento ou ainda pode ser ingerida quantidade de forragem insuficiente para sustentar níveis satisfatórios de crescimento e ganho (Poppi \& McLennan, 1995).

Em bovinos em crescimento, a proteína microbiana produzida no rúmen que atinge o intestino delgado pode não ser suficiente para atender à necessidade de proteína metabolizável (NRC, 2001). Desse modo, uma alternativa viável, desde que respeitado o mínimo necessário de nitrogênio ao crescimento microbiano, consiste em aumentar o nível de proteína nãodegradável no rúmen (PNDR) da ração para suprir o aporte de aminoácidos a serem absorvidos por esses animais, tendo em vista maximizar a síntese e resíntese de novos tecidos, o crescimento e o desempenho animal, conforme já evidenciado (Swanson et al., 1999; Bethard et al., 1997; Casper et al., 1994; Steen et al., 1992; Swartz et al., 1991). Pode-se inferir, então, que suplementos concentrados para novilhas em crescimento, formulados com elevados níveis de PNDR, favorecem ganhos diferenciados, a exemplo dos trabalhos realizados com novilhas nas fases de cria ou recria, a pasto ou em confinamento (Oliveira et al., 2001; Bethard et al., 1997; Tomlinson et al., 1997; Petit \& Yu, 1993).
O principal objetivo com a adoção da suplementação estratégica nos trópicos consiste em corrigir possíveis ou reais deficiências específicas da pastagem (Paulino et al., 2002; Euclides, 2002), isto é, fornecer mistura equilibrada de nutrientes de forma a potencializar a fermentação microbiana ruminal da fração digestível da parede celular vegetal, diminuir o tempo de permanência da fração indigestível no trato gastrintestinal, favorecer o consumo e, conseqüentemente, o desempenho, ou, ainda, quando se deseja imprimir taxas de crescimento e ganho acentuadas, torna-se necessário o aporte extra de nutrientes.

O trabalho foi conduzido com o objetivou de avaliar o consumo e o ganho de peso de novilhas leiteiras de reposição em sistema de pastejo rotacionado de Brachiaria brizantha cv. Marandu, durante os meses de março, abril e maio de 2001, recebendo suplementos com diferentes níveis de PNDR.

\section{Material e Métodos}

O experimento foi realizado no campus do Instituto Melon de Estudos e Pesquisas (IMEP), localizado na Fazenda Barreiro LTDA, município de Silvânia-GO. O município de Silvânia está localizado no planalto central goiano, cujas características de solo, clima, topografia e vegetação foram descritas por Oliveira et al. (2001).

A área total do experimento foi de 4,14 ha, divididos em 30 piquetes (10 piquetes/tratamento) de $1.200 \mathrm{~m}^{2}$ $(20 \times 60 \mathrm{~m})$ e três corredores centrais de $3 \times 600 \mathrm{~m}$. Na extremidade norte de cada corredor, havia baias cobertas, onde os animais recebiam o suplemento duas vezes ao dia (8 e 16 h), em comedouros individualizados com canzil, água e mistura mineral, além dos procedimentos experimentais (fornecimento de óxido de cromo, coleta de fezes, entre outros).

A pastagem de Brachiaria brizantha havia sido estabelecida a aproximadamente um ano. No experimento, empregou-se o sistema de pastejo rotacionado, com três dias de utilização e 27 de descanso.

Foram utilizadas 15 novilhas (5/tratamento) mestiças Gir x Holandês com idade inicial de 16,5 \pm 4,2 meses e peso vivo de $211,97 \pm 34,28 \mathrm{~kg}$, selecionadas em função do grau de sangue, da idade e do peso. Além destas, foi utilizado um número variável de animais reguladores, para manutenção da oferta de forragem em torno de 6\% do peso vivo em matéria verde seca (MVS). 
Os tratamentos consistiram de animais exclusivamente em pastagem de B. brizantha e de animais em pastagem de $B$. brizantha recebendo suplemento com 40 e 60\% de proteína não-degradável no rúmen (PNDR). Os alimentos foram selecionados considerando-se a disponibilidade, o preço no mercado local e o valor nutritivo. Para efeito de cálculo, considerouse que o teor de PNDR contido na forrageira era desprezível.

As quantidades oferecidas diariamente e as proporções dos ingredientes na composição final dos suplementos, assim como a composição bromatológica dos suplementos estão descritas na Tabela 1.

O experimento teve duração de 92 dias, divididos em três períodos, compreendendo os meses de março, abril e maio de 2001, nos quais foram feitas as repetições das avaliações de consumo, pesagem e ajustes da carga animal, conforme pré-estabelecido.

Durante os últimos 15 dias de cada período de 30 dias, foram realizadas as coletas, para determinação do consumo. O período de adaptação foi de nove e o de coleta de extrusas e fezes, de seis dias. No período de coleta, foram fornecidos aos animais-teste, $10 \mathrm{~g}$ de óxido crômico (5 g pela manhã e à tarde) como indicador externo, via oral, embalados em cartuchos de papel. Durante os seis dias finais, as amostras de fezes foram coletadas diretamente do reto de cada animal, às 8 e 16 h, e submetidas à pré-secagem em estufa de ventilação forçada por 72 a 96 h e $60 \pm 5^{\circ} \mathrm{C}$. Após pré-seca, uma parte das amostras fecais individuais foram trituradas em moinho tipo Willey com peneira com crivo de $5 \mathrm{~mm}$ (ensaio de degradabilidade) e outra parte, em moinho com peneira de $1 \mathrm{~mm}$ (determinação da composição centesimal). As amostras foram compostas tomando-se massas iguais por animal e tratamento, sendo, então, armazenadas adequadamente, para análises subseqüentes.

A coleta de extrusas foi feita utilizando-se seis animais castrados (2/tratamento), com peso vivo de $380 \pm 62 \mathrm{~kg}$, de diferentes graus de sangue e providos de fistulas no esôfago, após privação de alimento sólido por aproximadamente 16 horas.

Foram feitas análises nos alimentos, nas fezes e nas extrusas dos teores de proteína bruta (PB) corrigida para lisina e EDTA, matéria mineral (MM) e extrato etéreo (EE), expressos em $\mathrm{g} / \mathrm{kg}$ na base da matéria seca (MS), conforme AOAC (1990). As concentrações de fibra em detergente neutro (FDN) nas extrusas, nas fezes e nos ingredientes dos concentrados foram
Tabela 1 - Composição, quantidade oferecida e teores médios de proteína bruta (PB), fibra em detergente neutro, carboidratos fibrosos (CF) e carboidratos totais (CT) nos suplementos com $40\left(\mathrm{~T}_{40}\right)$ e $60 \%\left(\mathrm{~T}_{60}\right)$ de PNDR

Table 1 - Composition, amount fed, and average contents of crude protein (CP), neutral detergent fiber (NDF), fiber carbohydrates (FC) and total carbohydrates (TC) in supplements with 40 (T40) or 60\% (T60) RUP

\begin{tabular}{lcc}
\hline \multirow{2}{*}{$\begin{array}{l}\text { Ingrediente } \\
\text { Ingredient }\end{array}$} & \multicolumn{2}{c}{ Suplemento $^{1}$} \\
\cline { 2 - 3 } Supplement $^{1}$
\end{tabular}

${ }^{1} \mathrm{~g} / \mathrm{kg} \mathrm{MS} ;{ }^{2} \mathrm{~g} \mathrm{MS} / \mathrm{dia}$.

${ }^{1} \mathrm{~g} / \mathrm{kg} \mathrm{DM} ;{ }^{2} \mathrm{~g} D \mathrm{D} / \mathrm{day}$.

determinadas segundo procedimento descrito por Van Soest et al. (1991), enquanto os teores de carboidratos fibrosos (CF) foram obtidos descontando-se da FDN os teores de cinza e proteína, determinados nos resíduos insolúveis em detergente neutro.

As proporções de carboidratos totais foram determinadas pela expressão: CT (g/kg de MS) = [1000 $(\mathrm{PB}+\mathrm{EE}+\mathrm{MM})]$ (Sniffen et al., 1992) e os teores de carboidratos não-fibrosos (CNF), pela expressão $\mathrm{CNF}=\mathrm{CT}-\mathrm{CF}$ (NRC, 2001).

O conteúdo de cromo nas amostras de fezes foi determinado por espectrometria de absorção atômica, conformemetodologia propostaporWilliams et al.(1962).

A produção de matéria seca fecal foi estimada com base no teor de cromo, por meio da equação: $P F=\frac{q}{c}$, em que: $P F=$ produção de matéria seca fecal, kg de MS fecal/novilha/dia; q = quantidade de cromo oferecida diariamente por animal, em mg; $\mathrm{c}=$ concentração de cromo nas fezes, $\mathrm{mg} \mathrm{Cr} / \mathrm{kg}$ de MS fecal. 
A concentração de fibra em detergente neutro indigerível (FDNI), empregada como indicador interno nas estimativas de consumo, foi determinada nas extrusas, nos ingredientes dos suplementos e nas fezes das novilhas adotando-se procedimento único, por meio da técnica da bolsa de náilon (Cochran et al., 1986). Foram utilizados dois animais por tratamento, sendo incubadas três repetições para fezes e volumoso e cinco para os ingredientes dos suplementos para cada tempo de incubação. O tempo de incubação ruminal para fezes e concentrados foi de 144 horas, enquanto, para extrusa, os tempos foram $3 ; 6 ; 9 ; 12 ; 24$; 36;72 e 96 horas, além do tempo zero hora, cujo valor equivale àquele da FDN obtido na determinação direta descrita anteriormente. Ao final do período de ensaio, as amostras foram submetidas ao mesmo protocolo de determinação da FDN (Van Soest et al., 1991).

O procedimento inicial para a estimativa de consumo de forragem a partir da FDNI foi o da apreciação visual dos perfis de degradação em gráfico cartesiano. Os perfis de degradação da fibra, por tratamento e período, deram origem aos dados de entrada no programa estatístico SAS (1997), para interpretação da cinética de degradação e obtenção da estimativa dos parâmetros U, I, $c$ e $p$ por meio do modelo logístico decrescente proposto por Van Milgen et al. (1991), considerado por Vieira et al. (1997) o mais adequado a perfis de degradação sigmoidal, em que U (g/kg de MS) equivale à fração insolúvel, mas potencialmente degradável e não-disponível para digestão até o término do período de latência, que se torna gradualmente disponível à razão $\mathrm{p}\left(\mathrm{h}^{-1}\right)$; a fração U disponibilizada passa a ser denominada A, cuja taxa de digestão é descrita por c $\left(\mathrm{h}^{-1}\right)$; e I (g/kg de MS) representa a fração indegradável, que não mais se altera em função do tempo, por ação microbiana. Multiplicando-se a fração indegradável padronizada (Ip), expressa por: $\mathrm{Ip}=\mathrm{I}(0) /[\mathrm{U}(0)+\mathrm{I}(0)$ pelo teor de FDN da extrusa obteve-se a concentração de FDNI, cuja média das observações foi empregada como indicador interno na estimativa de consumo do pasto. A FDNI dos ingredientes e fezes foi obtida diretamente no resíduo indigestível após incubação por 144 horas. Assim, empregou-se, na determinação do consumo de matéria seca da forragem, do suplemento e da dieta total, a relação: $\mathrm{CMS}_{\mathrm{P}} \times \mathrm{FDNI}_{\mathrm{P}}$ $=\mathrm{PF} \times \mathrm{FDNI}_{\mathrm{F}}-\mathrm{CMS}_{\mathrm{S}} \times \mathrm{FDNI}_{\mathrm{S}}$, em que: $\mathrm{CMS}_{\mathrm{P}}=$ consumo de matéria seca da forragem, kg/dia; FDNI $_{\mathrm{P}}$ = concentração do indicador interno na forragem;
$\mathrm{PF}=$ produção fecal, $\mathrm{kg} /$ dia; $\mathrm{FDNI}_{\mathrm{F}}=$ concentração do indicador interno nas fezes; $\mathrm{CMS}_{\mathrm{S}}=$ consumo de matéria seca do suplemento, $\mathrm{kg} /$ dia; FDNI $_{\mathrm{S}}=$ concentração do indicador interno no suplemento.

A partir do consumo de MS, estimou-se o consumo diário de PB, FDN e FDNI da forragem e da dieta total (pastagem + suplemento). Uma vez estimado o consumo dos nutrientes, estes foram ajustados para covariável massa média individual dos animais de todo o período experimental, por meio da equação descrita por Kleiber (1975) e Brody (1945): $Y_{i}=\alpha \times m_{i}^{\beta}+e_{i}$, em que: $\mathrm{y}=$ variável consumo dependente; $\alpha=$ constante da equação; $\beta=$ valor de proporcionalidade entre as variáveis dependente e independente; $\mathrm{m}$ = massa média individual dos animais; $\mathrm{e}_{\mathrm{i}}=$ erro associado à observação.

As amplitudes aleatórias atribuídas ao modelo foram obtidas a partir dos valores próximos àqueles observados (para os coeficientes a e b) por meio da linha de tendência e do coeficiente de determinação da equação estabelecida. Em seguida, procedeu-se à verificação da necessidade de ajuste utilizando-se o programa estatístico SAS (1997), que, após processamento dos dados, retorna o valor do parâmetro estimado da equação alométrica para ajustar o consumo em função da covariável $(\beta)$ e do intervalo de confiança assintótico da relação biológica $\left(\mathrm{I}_{\mathrm{C}}\right)$. A tomada de decisão foi realizada considerando-se as hipóteses: $\mathrm{H}_{0}: \beta=0$ e $\mathrm{H}_{1}: \beta \neq 0$. Nos casos em que o $\mathrm{I}_{\mathrm{C}}$ continha o valor zero, não se rejeitava $\mathrm{H}_{0} \mathrm{e}$, portanto, a variável consumo não foi ajustada para a covariável. Nos casos em que o $\mathrm{I}_{\mathrm{C}}$ não continha o valor zero, rejeitava-se $\mathrm{H}_{0}$ e, portanto, a variável consumo foi ajustada para a covariável, de acordo com a expressão: $Y_{i j k}($ ajustado $)=\frac{Y_{i j k}}{M_{i j k}^{\hat{\beta}}}$.

A partir da diferença entre a massa do início e do final de todo experimento, foram obtidos os ganhos de peso total e médio diário de cada novilha. As pesagens foram feitas sempre no início da manhã, após jejum de 16 horas. Por ocasião das pesagens, foram efetuados os ajustes de carga à oferta de forrageira pretendida, 6\% do peso vivo em MSV/dia, conforme Paladines \& Lascano (1982), $P V t=\frac{M V S \times A}{O F \times P O} \times 100$, em que: $\mathrm{PVt}=$ peso vivo dos animais a serem colocados no piquete, em kg; MVS = quantidade de matéria verde 
seca, em $\mathrm{kg} / \mathrm{ha} ; \mathrm{A}$ = área do piquete, em ha; $\mathrm{OF}=$ oferta de forragem, definida como kg de MVS/ 100 kg PV por dia; PO = dias de ocupação do piquete.

Os valores obtidos para consumo, ajustados ou não para a covariável, foram analisados segundo o delineamento inteiramente casualizado, em esquema fatorial, no qual interagiam tratamento e período. As análises de ganho de peso foram efetuadas segundo o delineamento inteiramente casualizado, adotando-se o nível de 0,05 de significância e o teste Tukey para avaliação comparativa das médias. Posteriormente, foram ajustadas as equações de regressão para tratamento dentro de cada período experimental, com base no nível descritivo do teste $\mathrm{F}$ aplicado aos efeitos linear e quadrático dos $\hat{\beta}_{s}^{\prime}$, considerando-se o efeito como significativo quando $P \leq 0,05$.

\section{Resultados e Discussão}

Foram encontrados efeitos significativos de tratamento, período e interação tratamento $\times$ período para todas as variáveis de consumo de forragem e da ração total analisadas, não havendo efeito de tratamento apenas para consumo de matéria seca (CMS) e PB da ração total $(\mathrm{P}>0,05)$ (Tabela 2$)$.

Os consumos de matéria seca e de PB praticados pelas novilhas em recria exclusivamente a pasto decresceram à medida que se aproximava a estação seca propriamente dita, com valores médios observados de 153 e 95 g/kg de PV-0,75/dia, para MS, e 25 e 7 g/kg de PV-0,75/dia, para PB, respectivamente, nos meses de março e maio. Quanto ao consumo de FDN (Tabela 2), observou-se substancial redução do primeiro período para os períodos subseqüentes. Em contrapartida, a ingestão de FDNI ajustada elevou de 7 para $10 \mathrm{~g} / \mathrm{kg}$ de $\mathrm{PV}-0,9 /$ dia $(\mathrm{P} \leq 0,05)$ de março para maio.

Segundo Obara et al. (1991), em situações em que o suplemento passa a constituir mais de $25 \%$ da dieta total, observa-se, geralmente, redução no consumo total de forragem, fenômeno denominado efeito substitutivo. Este critério abrange os valores de ingestão observados para os tratamentos com 40 e 60\% PNDR, cujos percentuais de participação do suplemento na dieta foram de 27,85 e 28,27\%, respectivamente. O grau e a magnitude de ocorrência do efeito substitutivo, no entanto, depende da disponibilidade (quantidade e qualidade) da pastagem oferecida (Euclides, 2002). Nas condições deste trabalho, em que a oferta de forragem foi mantida regular e constante em $6 \%$ PV em MVS/dia (Tabela 3), provavelmente a variação na qualidade da pastagem ao longo do tempo foi fator determinante na expressão numérica do efeito relatado.

O CMS total, nos tratamentos em que as novilhas receberam suplementação, foi ampliado (123, 85 e $119,108 \mathrm{~g} / \mathrm{kg}$ de $\mathrm{PV}^{-0,75} /$ dia), com redução significativa da ingestão de MS da pastagem de 92, 57 e 83, $80 \mathrm{~g} / \mathrm{kg}$ de $\mathrm{PV}^{-0,75} / \mathrm{dia}$ (tratamentos com 40 e $60 \%$ PNDR), respectivamente, de março a maio. Esse comportamento foi similar ao verficado por Dixon \& Stockdale (1999) e Obara et al. (1991).

Brody (1945) e Kleiber (1975), em seus estudos sobre os fenômenos e as interações da bioenergética animal, estabeleceram a relação $y=\alpha \times m^{\beta}$, partindo do princípio de que é uma constante a razão existente entre a produção de calor e a massa corporal do indivíduo elevada a um expoente de proporcionalidade $(\beta)$. A partir desta pressuposição e considerando-se o comportamento similar de consumo dos animais exclusivamente em pastagem ou em pastagem suplementada, especialmente no tocante à fração indigerível da pastagem, poder-se-ia postular que a capacidade de consumo observada é diretamente proporcional à massa média do animal elevada a uma constante de proporcionalidade, obtida pela aplicação da estimativa inicial da variável de consumo à equação representativa da relação biológica, isto é, Consumo $=\alpha \times m^{\beta}$. Mediante a aceitação dessa hipótese, a estimativa e expressão final da variável de consumo dar-se-ia em função da constante de proporcionalidade obtida, resultante da influência da massa média do animal em determinado estádio, e não aleatoriamente em uma das formas atuais de expressão (kg/dia, \%PV ou g/kg de $\mathrm{PV}^{-0,75} / \mathrm{dia}$ ). No caso deste estudo, procedendo-se de acordo com a pressuposição descrita anteriormente, observou-se que a capacidade de consumo de FDNI da forragem e da ração total foi influenciada $(\mathrm{P} \leq 0,05)$ pela massa média das novilhas ao longo do tempo de experimentação, enquanto as demais variáveis de consumo não foram afetadas pela covariável. Assim, considerando verdadeiro o princípio da relação biológica proposto, afirmar-se-ia a hipótese de Vieira et al. (1997) de que a fração indigerível da parede celular vegetal das forrageiras tropicais constitui-se no principal componente causador da repleção ruminal e, conseqüentemente, da redução do consumo e do desempenho. 
Tabela 2 - Valores médios de consumos de matéria seca, proteína bruta, fibra em detergente neutro e fibra em detergente neutro indigerível da forragem e da ração total (pastagem + suplemento), expressos em g/kg-0,75/dia para período dentro de tratamento $\left(\mathrm{T}_{0}=\right.$ pastagem exclusiva; $\mathrm{T}_{40}=$ pastagem acrescida de suplemento com $40 \%$ de PNDR; $\mathrm{T}_{60}=$ pastagem acrescida de suplemento com $60 \%$ de PNDR), e equações de regressão ajustadas para tratamentos dentro dos períodos 1, 2 e 3

Table 2 - Average values of intake of dry matter, crude protein, neutral detergent fiber and indigestible neutral detergent fiber of pasture and total diet (pasture + supplement) expressed in $\mathrm{g} / \mathrm{kg}-0.75 /$ day for periods within treatments, and regression equations adjusted for treatments $\left(T_{0}=\right.$ pasture exclusively; $T_{40}=$ pasture plus supplement with $40 \%$ of RUP; $T_{60}=$ pasture plus supplement with $60 \%$ of RUP) within periods 1,2 e 3

\begin{tabular}{|c|c|c|c|}
\hline \multirow{2}{*}{$\begin{array}{l}\text { Período } \\
\text { Period }\end{array}$} & \multicolumn{2}{|c|}{$\begin{array}{c}\text { Tratamento } \\
\text { Treatment }\end{array}$} & \multirow[t]{2}{*}{$\begin{array}{l}\text { Equação } \\
\text { Equation }\end{array}$} \\
\hline & $\mathrm{T} 40$ & T60 & \\
\hline
\end{tabular}

Matéria seca do pasto

Pasture dry matter

P1

P2

P3

Matéria seca total

Total dry matter

$\mathrm{P} 1$

P2

P3

Proteína bruta da forragem

Pasture crude protein

P1

P2

P3

Proteína bruta total

Total crude protein

P1

P2

P3

FDN da forragem

Pasture NDF

P1

P2

P3

FDN da ração total

NDF of the total diet

P1

P2

P3

FDN indigerível da forragem ${ }^{2}$

Indigestible NDF of pasture ${ }^{2}$

P1

P2

P3

FDN indigerível da ração total ${ }^{2}$ Indigestible NDF of total diet ${ }^{2}$

P1

P2

P3

$153 \mathrm{a}^{1}$
$100 \mathrm{~b}$
$95 \mathrm{~b}$

\section{$92 \mathrm{a}$}

$78 \mathrm{~b}$

83 a

$58 \mathrm{~b}$

$57 \mathrm{c}$

$153 \mathrm{a}$

123 a

$100 \mathrm{~b}$

$107 \mathrm{~b}$

$95 \mathrm{~b}$

85 c

$119 \mathrm{a}$

$88 \mathrm{c}$

$108 \mathrm{~b}$

80 a

25 a

7 c

$12 \mathrm{a}$

8 b

$4 \mathrm{c}$

13 a

5 a

6 a

25 a

$9 \mathrm{~b}$

7 c

17 a

$12 \mathrm{~b}$

$8 \mathrm{c}$

18 a

$10 \mathrm{~b}$

$11 \mathrm{~b}$

107 a

$69 \mathrm{~b}$

70 b

60 a

53 a

$40 \mathrm{~b}$

59 a

39 b

59 a

107 a

$69 \mathrm{~b}$

70 b

66 a

$58 \mathrm{a}$

62 a

45 a

$42 \mathrm{~b}$

62 a

$7 \mathrm{c}$

$5 \mathrm{c}$

5 c

$8 \mathrm{~b}$

$10 \mathrm{a}$

$$
7 \mathrm{a}
$$

$6 \mathrm{~b}$

$6 \mathrm{~b}$

7 a

$7 \mathrm{c}$

8 b

$10 \mathrm{a}$
5 c

$7 \mathrm{a}$

6 b

$$
\begin{gathered}
\hat{Y}=1,53 \times 10^{2}-2,39 X+2,14 \times 10^{-2} X^{2} \\
\hat{Y}=1,01 \times 10^{2}-6,77 \times 10^{-1} X \\
\hat{Y}=9,51 \times 10^{1}-2,35 X+3,49 \times 10^{-2} X^{2}
\end{gathered}
$$

$$
\begin{gathered}
\hat{Y}=1,52 \times 10^{2}-5,97 \times 10^{-1} X \\
\hat{Y}=9,85 \times 10^{1} X \\
\hat{Y}=9,51 \times 10^{1}-1,23 X+2,41 \times 10^{-2} X^{2}
\end{gathered}
$$

\footnotetext{
${ }^{1}$ Médias seguidas de letras diferentes na coluna, diferem $(P \leq 0,05)$ pelo teste Tukey; ${ }^{2} \mathrm{~g} / \mathrm{kg}-0,9 / \mathrm{dia}$.

${ }^{1}$ Means followed by different letters in the same column differ $(P \leq 0.05)$ by Tukey test. ${ }^{2} \mathrm{~g} / \mathrm{kg}-0.9 /$ day.
} 
Tabela 3 - Médias, desvio-padrão e limites inferior e superior para pressão de pastejo observada em relação à pretendida ${ }^{1}$, obtidos pelo teste $\mathrm{t}$ a 0,05 de significância

Table 3 - Means, standard deviation and upper and lower limits for observed pressure of pasture versus expected, obtained by $t$ test at 0.05 of significance

\begin{tabular}{lcccc}
\hline $\begin{array}{l}\text { Tratamento } \\
\text { Treatment }\end{array}$ & $\bar{x}^{2}$ & $s(\bar{x})$ & LI & LS \\
\hline T0 & 6,12 & 0,69 & 5,86 & 6,37 \\
T40 & 6,10 & 0,60 & 5,88 & 6,32 \\
T60 & 5,98 & 0,75 & 5,71 & 6,26 \\
Geral & 6,07 & 0,68 & - & -
\end{tabular}

1 6\% do PV em MSV/dia; 2 pressão de pastejo observada (\% PV em MSV/dia).

${ }^{1} 6 \%$ of BW in MSV/day; ${ }^{2}$ observed pressure of pasture (\% BW in MSV/day).

Na Tabela 2 encontram-se as equações da regressão ajustadas, de acordo com a significância do maior grau $(\mathrm{P} \leq 0,05)$, para os níveis de PNDR nos diferentes períodos. O nível de PNDR influenciou o consumo de forragem em todos os períodos (meses) experimentais. Conforme pesquisas anteriores, o efeito da adição de PNDR sobre o CMS é variável e de difícil predição. Swartz et al. (1991) relataram que a incorporação de PNDR promoveu queda no CMS. Entretanto, Oliveira et al. (2001) e Petit \& Yu (1993) não verificaram mudanças no consumo diário com o aumento na proporção de PNDR.

A ingestão média de MS da dieta total observada neste experimento, foi de 116, 105 e 105 g/kg de $\mathrm{PV}^{-0,75 / d i a, ~ r e s p e c t i v a m e n t e, ~ p a r a ~ o s ~ t r a t a m e n t o s ~ p a s-~}$ tagem exclusiva e pastagem + suplemento com 40 e $60 \%$ de PNDR da PB total. Esses valores são ligeiramente superiores aos recomendados pelo NRC (2001), que é de $98 \mathrm{~g} / \mathrm{kg}$ de $\mathrm{PV}^{-0,75} / \mathrm{dia}$, para novilhas leiteiras.

Resultados inferiores aos encontrados são relatados por Oliveira et al. (2001). Estes autores, trabalhando com novilhas Pardo-Suíças na mesma unidade experimental, no período seco, recebendo suplementos com 60, 40 e 20\% de PNDR, observaram consumo médio total de $90 \mathrm{~g} / \mathrm{kg}$ de $\mathrm{PV}^{-0,75} / \mathrm{dia}$, que foi similar àquele relatado por Tomlinson et al. (1997), ao elevarem o nível de PNDR de 31 para 55\% da PB da ração.

Resultados similares ao valor médio total encontrado (108 g/kg de $\mathrm{PV}^{-0,75 / d i a) ~ s a ̃ o ~ d e s c r i t o s ~ p o r ~}$ Casper et al. (1994), que, trabalhando com níveis de 35 e 45\% PNDR para novilhas com peso vivo médio de $220 \mathrm{~kg}$, encontrou consumo médio de 104 g/kg de $\mathrm{PV}^{-0,75} /$ dia. Swartz et al. (1991) verificaram consumos médios de 114, 116 e 107 g/kg de $\mathrm{PV}^{-0,75} /$ dia para novilhas com peso corporal médio de 108,9 kg rece- bendo suplemento com 30, 34 ou 38\% de PNDR por um período de 11 semanas.

O nível de adição de PNDR influenciou significativamente $(\mathrm{P} \leq 0,05)$ o consumo de proteína bruta (CPB) da forragem e da ração total (Tabela 2). Quando se observa o CPB proveniente da forragem, verifica-se que a pastagem exclusiva foi suficiente para atender às exigências $\left(13,2 \mathrm{~g} / \mathrm{kg}\right.$ de $\mathrm{PV}^{-0,75} / \mathrm{dia}$; NRC, 2001) de ganho esperado somente no mês de março, quando o teor protéico da pastagem oferecida estava elevada (25, 12 e 13 g/kg de $\mathrm{PV}^{-0,75} /$ dia, respectivamente, para os tratamentos pastagem e pastagem acrescida de suplemento com 40 ou $60 \%$ PNDR). Entretanto, nos demais períodos, em que o teor protéico da forrageira reduziu o fornecimento de aproximadamente $1,8 \mathrm{~kg}$ MS/novilha/dia em forma de suplemento contendo 40 ou $60 \%$ de PNDR da PB total, o CPB não foi suficiente para atender às exigências.

Ao analisar os efeitos da ingestão de FDN provenientes da forragem e da ração total, observa-se comportamento similar, com efeitos quadrático, linear e quadrático, nos períodos 1, 2 e 3 . Conquanto, quando se observa o consumo de FDN exclusivamente da forragem, verifica-se valores de 1,94; 1,19 e 1,21\% PV e, quando acrescido de suplemento, o consumo total de fibra passou para 1,31 e 1,29\% PV/dia, respectivamente, em pastagem ou pastagem + suplemento com 40 e $60 \%$ PNDR.

Valores médios inferiores a estes foram relatados por Oliveira et al. (2001), que observaram que o valor de 0,90 a $1,16 \% \mathrm{PV} /$ dia está dentro de uma faixa ótima e não limitante do consumo. Segundo Mertens (1987), para animais em crescimento, o consumo de fibra deve ser em torno de 1\% PV/dia sob pena de limitar o consumo, em decorrência do efeito do enchi- 
mento ruminal. Considerando-se os valores de ingestão de FDN praticados pelas novilhas, pode-se que, provavelmente, a ingestão voluntária também foi afetada pela limitação física do espaço ruminal, pois boa parte do total de FDN consumida corresponde à fração indigestível, a quem se atribui importante participação na repleção ruminal.

Na Tabela 4 encontram-se os dados de desempenho das novilhas, em função dos níveis de PNDR no suplemento, o nível descritivo (valor P) do efeito observado e a equação ajustada para tratamento. Nota-se que o fornecimento de suplementos com níveis crescentes de PNDR (40 ou 60\%), quando comparados entre si ou com o ganho obtido exclusivamente em pastagem, não proporciona incrementos de ganhos diferenciados $(\mathrm{P} 0,05)$ no período de transição águas-seca.

Segundo Erasmus et al. (1994 a,b) e Zimmerman et al. (1994), um número variável de respostas é obtido ao se incluir PNDR à ração de animais em crescimento e/ou produção, desde respostas positivas, pequenas até nenhuma. Para esses autores, as prováveis razões para o leque de respostas normalmente encontradas ao adicionar PNDR à alimentação dos animais são: 1 ) redução da síntese de proteína microbiana decorrente da baixa disponibilidade de amônia, aminoácidos, peptídeos e energia; 2) indigestão da PNDR ou não-absorção no intestino delgado; 3) baixa qualidade, isto é, valor biológico representado pelo perfil de aminoácidos da fonte original de PNDR pobre ou deficiente.

A ausência de respostas significativas e diferenciadas das novilhas alimentadas com ou sem suplementação da pastagem possivelmente se deve à expressão, isolada ou em combinação, dos fatores supracitados. Todavia, à medida que se aumenta o fornecimento de proteína verdadeira (PNDR), maior a dependência do valor biológico da fonte de proteína, tendo em vista o atendimento das exigências da categoria animal em questão. Como mencionado, a PNDR oferecida provém basicamente de derivados do milho (fubá, glúten e gérmen), o que pode ter contribuído significativamente para a inexistência de ganhos diferenciados, uma vez que lisina e metionina são os primeiros aminoácidos limitantes à síntese de tecidos corporais e, portanto, do crescimento animal (NRC, 2001).

A não-observação de ganhos diferenciados entre os tratamentos empregados confirma os resultados obtidos por Steen et al. (1992), que, trabalhando com
Tabela 4 - Valores médios para peso vivo inicial (PVI), peso vivo final (PVF), ganhos médios totais (GMT) e diários (GMD) em função dos diferentes tratamentos (T0 = pastagem exclusiva; $\mathrm{T} 40=$ pastagem acrescida de suplemento com 40\% de PNDR; T60 = pastagem acrescida de suplemento com $60 \%$ de PNDR), níveis descritivos e equação de regressão ajustada para ganho médio diário

Table 4 - Average values of the initial body weight (IBW), final body weight (FBW), total average gain (TAG) and daily average gain (DAG) in response to different treatments $(T 0=$ pasture exclusively; $T 40=$ pasture increased of supplement with $40 \%$ of RUP; T60 = pasture plus supplement with $60 \%$ of RUP), descriptive levels, and regression equation adjusted for daily average gain

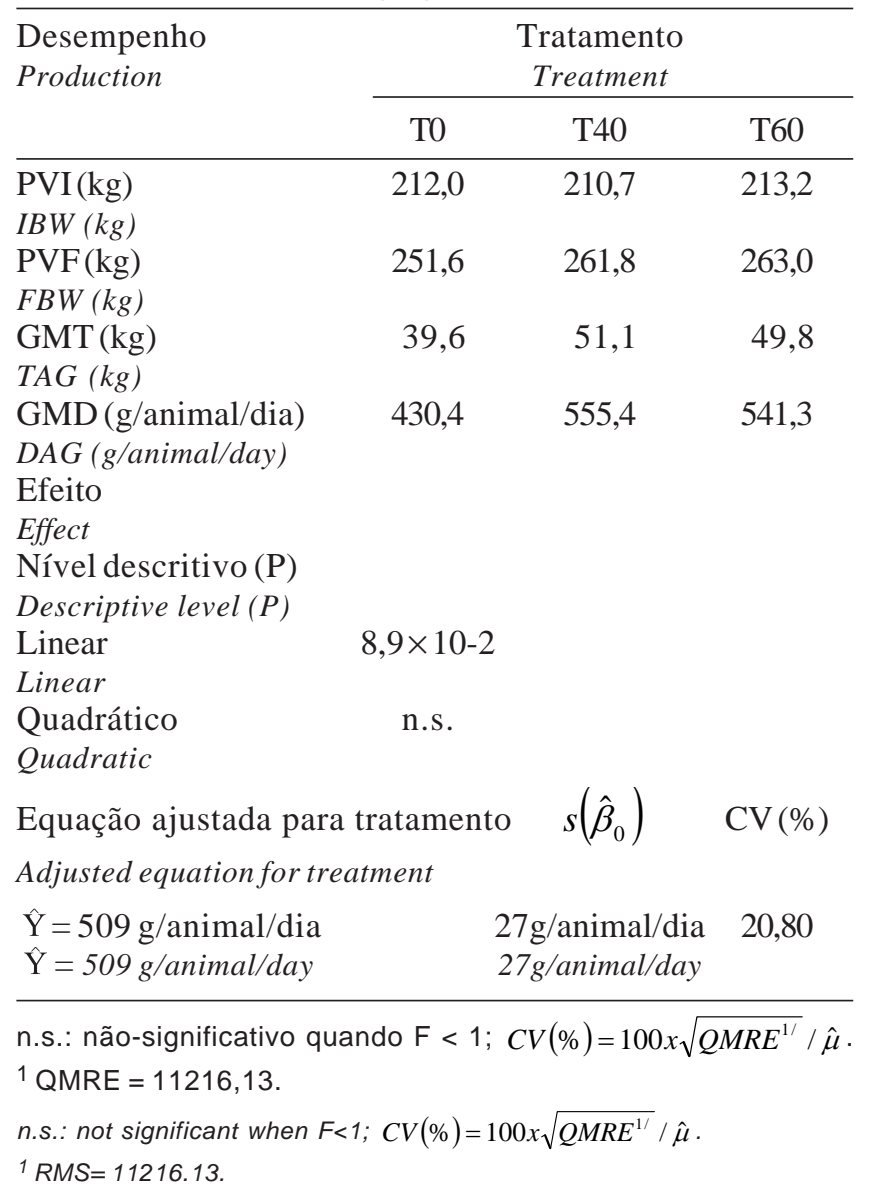

novilhas holandesas (253 kg) recebendo dois níveis de PNDR (32 ou 42\%), não verificaram diferenças significativas de ganhos entre os níveis propostos. Contudo, os ganhos relatados por esses autores foram superiores (600 e $700 \mathrm{~g} / \mathrm{dia}$ ) aos encontrados neste experimento.

Resultados divergentes são relatados por Oliveira et al. (2001), que, oferecendo $2,5 \mathrm{~kg} / \mathrm{cab} /$ dia de suplementos contendo baixa (20\%), média (40\%) ou alta (60\%) PNDR para novilhas Pardo-Suíças, no mesmo local em que se realizou este trabalho, verificaram 
ganhos significativamente distintos e expressivamente superiores (690b, 720a e 760a g/dia) aos encontrados neste estudo. Segundo os autores, os ganhos e as diferenças observadas se devem à maximização do crescimento microbiano e ao aporte de maior quantidade de aminoácidos metabolizáveis para o intestino delgado das novilhas.

Mesmo não sendo encontrada diferença nos ganhos proporcionados pelos suplementos com níveis crescentes de PNDR, parece adequado que, ao se incrementar a taxa de crescimento, com vistas à redução da idade ao primeiro parto e à entrada na vida produtiva, a quantidade de mistura concentrada que potencializa a fermentação microbiana e condiciona o fluxo mais adequado de aminoácidos para o trato digestivo inferior é aquela que encerra níveis próximos a $40 \%$ de PNDR da proteína bruta da ração.

\section{Conclusões}

A adição de suplemento proporcionou os efeitos complementares aditivo, expresso pelo ganho de peso, e substitutivo, caracterizado pela redução do consumo de matéria seca da forragem, com concomitante aumento no consumo de matéria seca da ração total.

O ganho de peso não foi influenciado pela adição de suplemento com níveis de 40 e 60\% de PNDR, quando comparados entre si e com o ganho exclusivamente em pastagem.

\section{Agradecimento}

Ao Instituto Melon de Estudos e Pesquisas e à Fazenda Barreiro Ltda, pelo apoio logístico concedido à realização deste trabalho.

\section{Literatura Citada}

ASSOCIATION OF OFFICIAL ANALYTICAL CHEMISTS AOAC. Official methods analysis. 15.ed. Arlington: 1990. $1117 p$.

BETHARD, G.L.; JAMES, R.E.; MCGILLIARD, M.L. Effect of rumen-undegradable protein and energy on growth and efficiency of growing Holstein heifers. Journal of Dairy Science, v.80, n.9, p.2149-2155, 1997.

BRODY, S. Bioenergetics and growth with special reference to the efficiency complex in domestic animals. In: BRODY, S. (Ed.) Bioenergetics and growth. Baltimore: Reinhold Publishing Corporation, 1945. p.352-403.

CASPER, D.P.; SCHINGOETHE, D.J.; BROUK, M.J. et al. Nonstructural carbohydrate and undegradable protein sources in the diet: growth responses of dairy heifers. Journal of Dairy Science, v.77, n.9, p.2595-2604, 1994.
COCHRAN, R.C.; ADAMS, D.C.; WALLACE, J.D. et al. Predicting digestibility of different diets with internal markers: evaluation of four potential markers. Journal of Animal Science, v.63, n.6, p.1476-83, 1986.

DIXON, R.M.; STOCKDALE, C.R. Associative effects between forages and grains: consequences for feed utilization. Australian Journal Agricultural Research, v.50, p.757-753, 1999.

ERASMUS, L.J.; BOTHA, P.M.; CRUYWAGEN, C.W. et al. Amino acid profile and intestinal digestibility in dairy cows of rumen-undegradable protein from various feedstuffs. Journal of Dairy Science, v.77, n.2, p.541-551, 1994a.

ERASMUS, L.J.; BOTHA, P.M.; MEISSNER, H.H. Effect of protein source on ruminal fermentation and passage of amino acids to the small intestine of lactating cows. Journal of Dairy Science, v.77, n.12, p.3655-3665, 1994b.

EUCLIDES, V.P.B. Estratégias de suplementação em pasto: uma visão crítica. In: SIMPÓSIO SOBRE MANEJO ESTRATÈGICO DA PASTAGEM, 3., 2002, Viçosa, MG. Anais... Viçosa, MG: Universidade Federal de Viçosa, 2002. p.437-469.

HOFFMAN, P.C.; FUNK, D.A. Applied dynamics of dairy replacement growth an management. Journal of Dairy Science, v.75, n.9, p.2504-2516, 1992.

KLEIBER, M. The fire of life: an introduction to animal energetics. 2.ed. New York: Robert E. Krieger Publishing Corporation, 1975. 454p.

MERTENS, D.R. Predicting intake and digestibility using mathematical models of ruminal function. Journal of Animal Science, v.64, n.6, 1548-1558, 1987.

NATIONAL RESEARCH COUNCIL - NRC. Nutrient of requirements of dairy cattle. 7. ed. Washington, D.C.: National Academic Press, 2001. 362p.

OBARA, Y.; DELLOW, D.W.; NOLAN, J.V. The influence of energy-rich supplements on nitrogen kinetics in ruminants. In: TSUDA, T.; SASAKI, Y.; KAWASHIMA, R. (Eds.) Physiological aspects of digestion and metabolism in ruminants. New York: Academic Press, 1991. p.515-539.

OLIVEIRA, R.L.; PEREIRA, J.C.; NASCIMENTO JÚNIOR, D. et al. Performance of Brown-swiss heifers in Brachiaria brizantha rotational grazing receiving supplements with rúmenundegradable protein. Biotechnology in Animal Husbandry, v.17, n.5-6, p.107-112, 2001.

PACIULLO, D.S.C. Características anatômicas relacionadas ao valor nutritivo da gramíneas forrageiras. Revista Ciência Rural, v.32, n.2, p.357-364, 2002.

PALADINES, O.; LASCANO, C. In: Recomendaciones para evaluar germoplasma ajo pastoreio en pequeños potreros. In: PALADINES, O.; LASCANO, C. (Eds.) Germoplasma forrageiro bajo pastoreio en pequeñas parcelas: Metodologia de evaluación. Memórias de una reunion de trabajo celebrada en Cali, Colômbia. Cali: CIAT, 1982. p.165-183.

PAULINO, M.F.; ZERVOUDAKIS, J.T.; MORAES, E.H.K. et al. Suplementação múltipla para bovinocultura de ciclo curto em pastagens. In: SIMPÓSIO DE PECUÁRIA DE GADO DE CORTE, 2., 2002, Lavras. Anais... Lavras: Universidade Federal de Lavras, 2002. p.199-252.

PETIT, H.V.; YU, Y. Use of protein supplements for dairy heifers fed fresh grass. Journal of Dairy Science, v.76, n.3, p.798-802, 1993.

POPPI, D.P.; McLENNAN, S.R. Protein and energy utilization by ruminants at pasture. Journal of Animal Science, v.73, n.1, p.278-290, 1995. 
SNIFFEN, C.J.; O’CONNOR, J.D.; Van SOEST, P.J. et al. A net carbohydrate and protein system for evaluating cattle diets: II. Carbohydrate and protein availability. Journal of Animal Science, v.70, n.12, p.3562-3577, 1992.

STATISTICAL ANALYSES SYSTEMS - SAS. User's guide: basics. 7.ed. Cary: 1997. 1290p.

STEEN, T.M.; QUIGLEY, J.D.; HEITMANN, R.N. et al. Effects of lasocid and undegradable protein on growth and body composition of Holstein heifers. Journal of Dairy Science, v.75, n.9, p.2517-2523, 1992.

SWANSON, K.C.; REDMER, D.A.; REYNOLDS, L.P. et al. Ruminally udegraded intake protein in sheep fed low-quality forage: effect of weight, growth, cell proliferation, and morphology of visceral organs. Journal of Animal Science, v.77, p.198-205, 1999.

SWARTZ, L.A.; HEINRICHS, A.J.; VARGA, G.A. et al. Effects of varying dietary undergradable protein on dry matter intake, growth, and carcass composition of Holstein calves. Journal of Dairy Science, v.74, n.11, p.3884-3890, 1991.

TOMLINSON, D.L.; JAMES, R.E.; BETHARD, G.L. et al. Influence of udegradability of protein in the diet on intake, daily gain, feed efficiency, and body composition of holstein heifers. Journal of Dairy Science, v.80, n.4, p.943-948, 1997.

Van MILGEN, J.; MURPHY, M.R.; BERGER, L.L. A compartmental model to analyze ruminal digestion. Journal Dairy Science, v.74, n.9, p.2515-2529, 1991.
Van SOEST, P.J.; ROBERTSON, J.B.; LEWIS, B.A. Methods for dietary fiber, neutral detergent fiber, and nonstarch polyssacharides in relation to animal nutrition. Journal of Dairy Science, v.74, n.10, p.3583-3597, 1991.

VIEIRA, R.A.M.; PEREIRA, J.C.; MALAFAIA, P.A.M. et al. Application of non-linear models in the description of in situ degradation profiles of the elephantgrass (Pennisetum purpureum Schum.). Animal Feed Science Technology, v.66, p.197-210, 1997.

ZIMMERMAN, C.A.; RAKES, A.H.; DANIEL, T.E. et al. Effect of total and rumen undegradable protein on the performance of cows fed low fiber diets. Journal of Dairy Science, v.75, n.7, p.1954-1965, 1992.

WILLIAMS, C.H.; DAVID, D.J.; IISMAA, O. The determination of chromic oxide in faeces samples by atomic absorption spectrophotometry. Journal of Agricultural Science, v.59, p.381-385, 1962.

Recebido em: 26/08/04

Aceito em: 01/07/05 